\title{
COLLAGENOLYTIC AND PHOSPHATASE ACTIVITY IN THE RAT MANDIBLE AFTER FUNCTIONAL PROTRUSION
}

\author{
A.-M. Bollen, ${ }^{1,2 *}$ K. K. MaKinen,' P.-L. MaKinen' and D. S. Carlson'² \\ 'Department of Biologic and Materials Sciences and 'Department of Orthodontics, University of Michigan, \\ School of Dentistry, Ann Arbor, MI 48109. U.S.A.
}

(Received 12 April 1988; accepted 28 September 1988)

\begin{abstract}
Summary-The effect of chronic mandibular protrusion on the collagenolytic and phosphatase activity of several mandibular bone sites and the condylar cartilage was evaluated. Ninety-three male Sprague-Dawley rats were equally divided into two experimental and one control group. One experimental group wore a protrusive appliance for 2 weeks, the other for 4 weeks. All animals were killed at 59 days of age. Coliagenolytic, alkaline and acid phosphatase activities were determined in the condylar cartilage, the subchondral bone and condylar neck, and in the gonial angle and coronoid process. In the cartilage and subchondral bone, the protrusive appliance caused a reduction in collagenolytic and alkaline phosphatase activity. In the condylar neck, it caused a large increase in collagenolytic activity and a decrease in alkaline phosphatase activity in both experimental groups. In the gonial angle and coronoid process, the appliance increased the collagenolytic activity only in the 2-week group. In the 4-week group, the alkaline phosphatase and collagenolytic activities were not different from the activities in those tissues in the control animals. Thus a protrusive appliance induced quantitative changes in enzyme activities in condylar cartilage and mandibular bone. The increase in collagenolytic activity (representing increased bone resorption) occurred typically in areas of muscle attachment and might have been the result of the neuromuscular changes induced by the protrusive appliance. The recovery to normal values of collagenolytic activity in the coronoid process and gonial angle of the 4-week group suggests that at these sites the muscles (and subperiosteal bone) might have adapted to their new biomechanical environment after the longer period of appliance wear.
\end{abstract}

\section{INTRODLCTION}

Changes in condylar cartilage proliferation and cartilage thickness occur after a change in the normal position and function of the mandible in young rats and monkeys (Charlier, Petrovic and HerrmannStutzmann, 1969; McNamara, 1973; McNamara and Carlson, 1979; Kantomaa, 1987). Experimental mechanical manipulation of the mandible into a more anterior position than normal also increases the overall length of the mandible (Petrovic, Stutzmann and Oudet, 1975; McNamara and Carlson, 1979; McNamara and Bryan, 1987). Mandibular growth, however, does not rely solely on condylar cartilage growth. Subperiosteal bone remodelling in several areas of the mandible is also responsible for the increase in mandibular length (Enlow, 1975). Therefore, the observed increase in length in response to mandibular protrusion is probably due to a combination of increased condylar cartilage proliferation and increased subperiosteal bone remodelling.

It is also well known that muscle function is a significant factor affecting bone growth and remodelling (Hoyte and Enlow, 1966). Because mandibular protrusion induces transient neuromuscular changes in all masticatory muscles (McNamara, 1973), an increase in bone remodelling might also be expected in areas of muscle attachment on the mandible. Previous studies on the effects of mandibular

-Address correspondence to: Anne-Marie Bollen. Department of Oral Biology, University of Michigan. School of Dentistry, Ann Arbor. MI 48109. U.S.A. protrusion on growth have emphasized the reaction of the condylar cartilage to mandibular protrusion (Petrovic et al., 1975). Our purpose was now to analyse biochemically the effects of mandibular protrusion on subperiosteal bone remodelling in several areas of the mandible. Collagenolytic and phosphatase activity were measured in the condylar cartilage, the subchondral bone and the condylar neck, as well as in areas of muscle attachment, the gonial angle and the coronoid process. Two different periods of protrusive-appliance wear were chosen to evaluate any adaptations to the appliance over time.

\section{MATERIALS AND METHODS}

\section{Experimental protocol}

Ninety-three male Sprague-Dawley rats, 31 days of age, were divided equally into two experimental groups and one control group. One experimental group was fitted with a mandibular protrusive appliance at the age of 31 days and wore the appliance for 4 weeks. The second experimental group was fitted with the appliance at the age of 45 days and wore it for 2 weeks. The control group did not wear an appliance. Because the experimental animals were unable to eat hard food, all animals were fed soft rat chow (standard rat chow powdered in water). The animals were weighed twice a week. All animals were killed at 59 days of age by an overdose of ketamine.

\section{Appliance design and appiication}

The protrusive appliance consisted of a piece of mesh wire spot-welded to a $7 \mathrm{~mm}$ long piece of 
orthodontic band which was curved to fit the upper incisors (Plate Fig. 1). All animals (including controls) were anaesthetized with a ketamine-rompin mixture. The upper incisors of the experimental animals were cleaned with pumice, acid-etched and the appliance bonded to them with a composite resin. The appliance produced $2 \mathrm{~mm}$ of mandibular protrusion and $2 \mathrm{~mm}$ of bite opening as determined radiographically. During the experimental period the animals were checked daily for the presence of the appliance. If an appliance had come off the animal was anaesthetized and a new appliance bonded in place.

\section{Sample preparation}

The mandibles were removed and cleaned of all soft tissue. Under a Wild stereo-zoom dissecting microscope, four mandibular sites were sampled for biochemical analysis (Text Fig.2): (1) the condylar cartilage; (2) the convex dome of new bone (about $1 \mathrm{~mm}$ thick) immediately beneath the condylar cartilage, consisting of spongy new bone and not comprising the external bone surface; (3) the neck of the mandibular condyle; and (4) two sites of muscle attachment, the gonial angle and coronoid process. Samples from each site were combined for all animals in each group to allow for detection of the low enzyme activities present in individual samples.

Pulverization, extraction and protein determination

The samples were frozen in liquid nitrogen and pulverized with a Braun micro-dismembrator for $2 \mathrm{~min}$. The resulting powder was extracted in $10 \mathrm{mM}$ tris- $\mathrm{HCl}$ buffer ( $\left.1 \mathrm{mM} \mathrm{Ca}{ }^{2+}, \mathrm{pH} 7.0\right)$ for $4 \mathrm{~h}$ at $4^{\circ} \mathrm{C}$ using a magnetic stirrer. The extracts were centrifuged at $22^{\circ} \mathrm{C}$ in an Eppendorf centrifuge 5413 for $15 \mathrm{~min}$ and the supernatants were recovered for biochemical studies. Protein content of the supernatants was measured using the Bio-Rad Protein Assay ${ }^{\mathrm{TM}}$ (Bradford, 1976); bovine plasma gamma globulin served as standard. All measurements were repeated six times and the means and standard deviations calculated.

\section{Collagenolytic activity}

The collagenolytic activity against $\left[{ }^{3} \mathrm{H}\right]$-rat tail tendon collagen type I in each sample was measured using a New England Nuclear ${ }^{\$ 3}$ Collagenase Assay System kit. The instructions in the manual were followed: accordingly, $10 \mu \mathrm{l}$ of each of the tissue extracts were added to the $\left[{ }^{3} \mathrm{H}\right]$-collagen mixtures
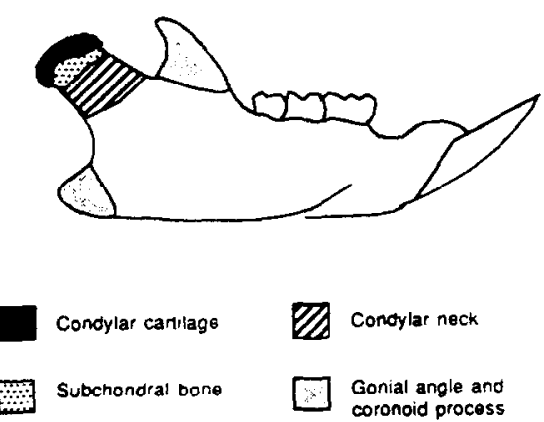

Fig. 2. Areas of the mandible that were analysed. after fibril formation $(10 \mu)\left[{ }^{3} \mathrm{H}\right]$-collagen with $80 \mu$ l of the supplied calcium buffer) and incubated for $24 \mathrm{~h}$ at $21^{\circ} \mathrm{C}$. Bacterial collagenase (Clostridium histolyricum, final level $0.01 \mathrm{mg} / \mathrm{ml}$ ), and vertebrate collagenase (tadpole, final level $0.01 \mathrm{mg} / \mathrm{ml}$ ) were used as reference enzymes; a substrate blank was also included. After incubation the samples were centrifuged $\left(12,000 \mathrm{~g}\right.$ for $10 \mathrm{~min}$ at $\left.4^{\circ} \mathrm{C}\right)$ and a $10 \mu 1$ sample of supernatant was added to $5 \mathrm{ml}$ of scintillation enhancer $\left(\mathrm{ACS}^{\mathrm{B}}, \mathrm{Amersham}\right)$. The radioactivity was measured with a scintillation counter (10 min for each sample). The collagenolytic activity was expressed as counts/min per mg protein

\section{Reaction products of the collagenolytic activity}

The reaction products of the incubation on $\left[{ }^{3} \mathrm{H}\right]$-collagen were studied using gel electrophoresis (SDS-PAGE) followed by autoradiography. The reaction mixtures were lyophilized, boiled in denaturation buffer for $2 \mathrm{~min}$ and run on PhastGel ${ }^{\mathrm{TM}}$ gels (gradient 8-25\%) with PhastGel SDS Buffer Strips on a Pharmacia PhastSystem Separation and Control Unit. The gels were fixed $(10 \%$ acetic acid, $30 \%$ methanol) for $1 \mathrm{~h}$ and radiation was enhanced in En $^{H}$ ance $^{T M}$ solution (New England Nuclear, Boston. Mass., U.S.A.) for $2.5 \mathrm{~h}$. They were then transferred to distilled water for $0.5 \mathrm{~h}$ and finally air-dried overnight at room temperature. followed by exposure for 4.5 days to Kodak XAR-5 film at $-76^{\circ} \mathrm{C}$.

\section{Assay's for alkaline and acid phosphatases}

The supernatants were assayed for alkaline and acid phosphatase activity using $p$-nitrophenyl phos. phate (Sigma 104) as substrate. in tris-HCl buffer (pH 9.1) and Mes- $\mathrm{NaOH}$ buffer (pH 5.0) respectively. The reaction mixtures consisted of $0.3 \mathrm{ml}$ buffer $(0.1 \mathrm{M}), 0.1 \mathrm{ml}$ substrate $(1 \mathrm{mM}), 0.1 \mathrm{ml} \mathrm{H}_{2} \mathrm{O}$ and $0.1 \mathrm{ml}$ enzyme $(10 \mu)$ tissue extract and $90 \mu \mathrm{l}$ $\mathrm{H}_{2} \mathrm{O}$ ). One unit will hydrolyse $1 \mu \mathrm{mol} p$-nitrophenyl phosphate per $30 \mathrm{~min}$ at $\mathrm{pH} 9.1$ (alkaline phos. phatase) or pH 5.0 (acid phosphatase) at $37^{\circ} \mathrm{C}$. The final results were expressed as $\mathrm{U} / \mathrm{mg}$ protein.

\section{Statistical analyses}

Animal weights. At the time of death these were compared for the three groups using one-way ANOVA followed by multiple comparisons between the three groups using Duncan's Multiple Range Test.

Collagenolytic and phosphatase activity. The data structure of this experiment made up a two-way table with two factors: (1) treatment group (control, 2 weeks experimental, and 4 weeks experimental), and (2) anatomical area (cartilage, condylar neck, etc.). For each of these two factors three response values were observed: collagenolytic activity, alkaline phosphatase and acid phosphatase activity. In this dataset only one observation per cell was made as the tissue samples were pooled. Therefore, a robust ex. planatory technique was preferred to techiques whose assumptions were difficult to check. A median polish was performed on the two-way table as follows. The median of each row was calculated and subtracted from every observation in the row. Then the medians of the columns of the resulting table were subtracted from the entries in its column. If a row or column had 
its median equal to zero, no changes were made in that row or column. This repeated process of subtracting medians (called 'median polish') can be repeated until all rows and columns have a zero median. Two complete iterations, however, are often enough to give row and column medians with small magnitudes compared to the residuals (the values left in each cell after the median polish; Emerson and Hoaglin, 1983). In our study, three complete iterations were done. The result of the median polish could be written as

$$
y_{1 j}=\mu+\alpha_{i}+\beta_{j}+\epsilon_{i j}
$$

where $\mu$ was the overall typical median, $\alpha$ was the row effect (tissue type) and $\beta$ was the column effect (animal group; Emerson and Hoaglin, 1983). This additive model (the explanation of the data as a simple sum or addition of various effects) was checked using a diagnostic plot. Residuals $(\epsilon)$ of treatment responses which were much smaller or larger than the other residuals (outliers) receive special attention in our Discussion as they cannot be explained satisfactorily by the model.
RESULTS

\section{Animal weights}

One-way ANOVA followed by Duncan's Multiple Range Test showed that the weights of the control group and the 4-week experimental group were not significantly different. The 2-week experimental group weighed significantly less $(6.3 \%)$ than the other groups $(p<0.05)$.

\section{Enzyme activities}

The collagenolytic activity was expressed in counts $/ \mathrm{min}$ per $\mathrm{mg}$ protein, and the phosphatase activities in U/mg protein (Text Fig. 3). Diagnostic plots used to investigate the additivity of the data (which is the expression of the data as the addition of several factors) indicated that natural logarithmic transformation of the data improved the model. Therefore, all statistical findings $(\mu, \alpha, \beta$ and $\epsilon)$ will be expressed as the natural logarithm.

Collagenolytic activity. After median polish, the value of $\mu$ for the collagenolytic activity was 3.30 . The effect of tissue type $(\alpha)$ for the cartilage and sub-

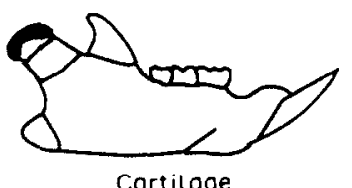

Cortiloge

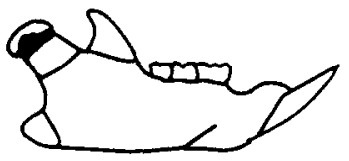

Subchondral bone

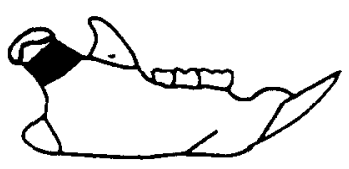

Condylor neck

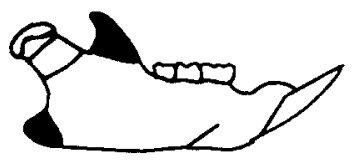

Gonial angle and coronoid process

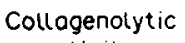
activity
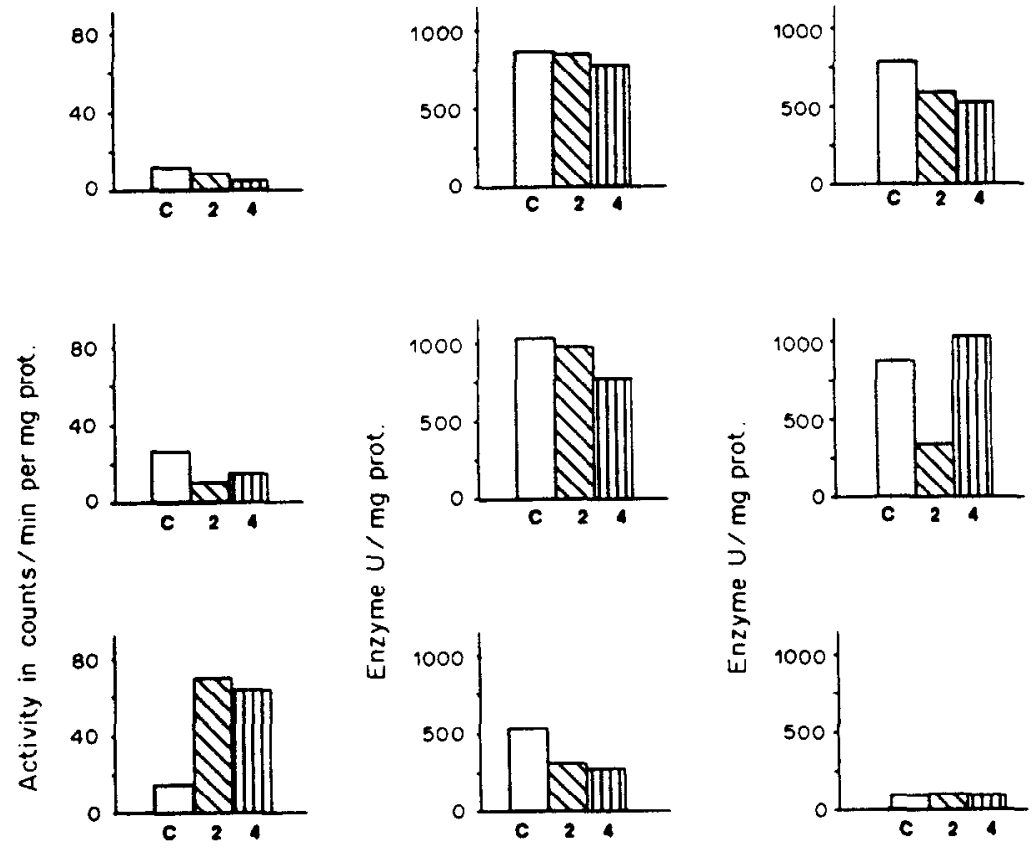

Fig. 3. Collagenolytic, alkaline and acid phosphatase activity in each of the analysed samples. $C=$ the control group $(n=31) ; 2=$ the experimental group that wore the protrusive appliance for 2 ueeks $(n=31): 4=$ the experimental group that wore the protrusive appliance for 4 weeks $(n=31)$. 
chondral bone $(-1.10$ and -0.40$)$ indicated an overall lower collagenolytic activity in these areas than in the condylar neck, gonial angle/coronoid process $(\alpha$ of +0.94 and +0.40 respectively). The effect of animal group $(\beta)$ showed increased collagenolytic activity in the 2-week experimental group ( $\beta$ of +3.06 compared to +0.18 for the control group and -0.09 for the 4-week group). The condylar neck of the control animals showed a large negative $\epsilon$ indicating that the collagenolytic activity in this area cannot be explained satisfactorily by tissue and animal group effects alone.

Reaction products of collagenolytic activity. Autoradiography showed that $\left[{ }^{3} \mathrm{H}\right]$-collagen type 1 was split into several smaller fragments, with molecular weights of about $30,000,33,000,50,000$ and 70,000 .

Alkaline phosphatase activity. The value of $\mu$ for the alkaline phosphatase activity was 6.60. The tissue effect for the cartilage and subchondral bone $(+0.16$ and +0.27$)$ indicated a higher alkaline phosphatase activity in these tissues than in the condylar neck and the gonial and coronoid processes $(-0.57$ and -0.12 ). There was a decrease in alkaline phosphatase activity in the experimental groups compared to the control group (group effect for the controls was 0.05 , compared to -0.04 and -0.12 for the 2 - and 4 -week experimental groups).

Acid phosphatase activity. The value of $\mu$ for the acid phosphatase activity was 5.61. The tissue effect for the cartilage and subchondral bone $(+0.80$ and $+1.19)$ indicated a higher acid phosphatase activity in these tissues than in the condylar neck and the gonial and coronoid processess $(-1.01$ and -0.95$)$. The animal-group effect showed no changes in response to the protrusive appliance. The acid phosphatase activity of the subchondral bone in the 2-week experimental animals had a large negative $t$ $(-1.10)$.

\section{DISCUSSION}

In view of current hypotheses about the neuromuscular and growth changes induced by mandibular protrusion, we expected increased bone. remodelling in several areas of the mandible in response to protrusion. The protrusive appliance was well tolerated and all animals gained weight. At the time of death, however, the 2-week experimental group weighed about $6.3 \%$ less than the two other groups. In similar experiments in our laboratory (J. W. Easton, personal communication) the tibiae of experimental animals with $11 \%$ less body weight than controls showed no difference in length. indicating that skeletal growth was probably not affected by gross weight differences. In those experiments no difference was found in the mass of the superficial masseter and lateral pterygoid muscles between experimental and control animals. The differences in enzyme activities between our 2-week experimental group and the two other groups are therefore more likely to be due to the different experimental procedure than to the difference in body weight.

The collagenolytic activities measured in the four mandibular sites resulted from the presence of soluble enzymes in active form in the tissue extracts. The $\left[{ }^{3} \mathrm{H}\right]$-collagen type I was split into several smaller chains, indicating increased extracellular matrix breakdown, as is found in sites of increased bone resorption. The results indicate that mandibular protrusion was associated with increased collagen breakdown in the condylar neck, gonial angle and coronoid process.

These findings are consistent with current theories of the effects of mandibular protrusive appliances. It is believed that mandibular protrusion causes transient, short-term neuromuscular changes in the masticatory muscles. Specifically, McNamara (1973) reported that the lateral pterygoid and superficial masseter muscles became hyperactive for a 6 -week period in rhesus monkeys wearing a protrusive appliance. Neuromuscular changes cause a different strain pattern on the underlying skeletal units, possibly causing bone resorption and bone remodelling (Lanyon, 1984). In our present study, the bone beneath the insertion of the temporalis muscle (coronoid process), the lateral pterygoid (condylar neck) and the masseter and medial pterygoid muscles (gonial angle) underwent extensive remodelling, probably because of changes in muscle activity caused by altering the length of the muscles. This increased bone remodelling could eventually lead to morphological changes. Gonial angle remodelling has indeed been shown in response to masseter muscle lengthening (Hendricksen et al., 1982). It should be noted that both the gonial angle and coronoid process also contain remnants of secondary cartilage within bone (Vinkka, 1982)

After 4 weeks of appliance wear, the collagenolytic activity in the gonial and coronoid processes was again similar to that of the controls. This could indicate that after 4 weeks the muscies and subperiosteal bone in the gonial angle and coronoid process had adapted to the new biomechanical environment. In the condylar neck the collagenolytic activity was still increased after 4 weeks of appliance wear. In the condylar neck, however, the increase in collagenolytic activity in response to the protrusive appliance can be explained on the basis not only of neuromuscular-induced bone remodelling, but also as an expression of increased mandibular growth, coinciding with anterior ramus resorption. Several experimental studies in rats have indeed shown that mandibular protrusion increases mandibular length (Petrovic, Stutzmann and Gasson. 1981). Increase of the length of the mandibular body is correlated with remodelling of the condylar neck. resorption of the ramus anteriorly and deposition of bone posteriorly.

The physiological role of acid and alkaline phosphatases is still not well understood. Several hypotheses have been proposed, the most usual indicating that alkaline phosphatase is a sign of bone formation and mineralization (Reddi and Huggins, 1972) and acid phosphatase of extracellular matrix degradation prior to calcification (Nilsen and Magnusson, 1981). Vertebrate alkaline phosphatase is a membranebound enzyme (Fernley, 1971). Because we did not use detergent in the extraction medium, we speculate that the recovered enzyme activity in the extract: results from either free alkaline phosphatase or alkaline phosphatase bound to small membrane particles Detergent extraction would have given much highet activity levels 
In the condylar cartilage and the subchondral bone layer, both alkaline and acid phosphatase activity were high compared with the more mature bone areas (condylar neck, and gonial and coronoid process). This agrees with histochemical studies (Silbermann and Frommer, 1973; Nilsen and Magnusson, 1981) that have shown a higlier prevalence of phosphatases in cartilage than in mineralized bone. Alkaline phosphatase activity decreased in response to the mandibular protrusion (except in the gonial and coronoid processess of the 4-week experimental animals). This decrease could indicate reduced bone formation, although correlation between alkaline phosphatase and bone deposition is questionable (Vilmann, 1977). It is also relevant that suppression of alkaline phosphatase in cell culture has been correlated with an increase in cell proliferation (Carpenter, 1981). In the condylar cartilage, mandibular protrusion caused a decrease in both acid and alkaline phosphatase activity. A similar result was reported by Copray, Jansen and Duterloo (1985) after the application of continuous compressive forces to the mandibular condyle in vitro. In the subchondral bone there was a large decrease in acid phosphatase activity in our 2-week experimental group, possibly suggesting decreased calcification. In the mature bone areas (condylar neck, gonial angle and coronoid process) the acid phosphatase activity was low and not affected by the mandibular protrusion.

Our results indicate that the protrusive appliance did induce quantitative changes in bone breakdown in several areas of the mandible. It is a combination of this increased bone remodelling, together with the previously reported increase in cartilage growth, that accounts for the overall change of mandibular size and morphology under the influence of a protrusive appliance On the basis of this study, the hypothesis that mandibular protrusion affects bone remodelling, probably through changes in the neuromuscular environment, cannot be rejected

Acknonledgements-This study was supported by grant DRI-DEO2731-21 and DEO3610. We wish to acknowledge Dr Eva Soderling for her valuable help and suggestions. and Dr D. Clewell for the use of his laboratory and equipment for the radioactive measurements in this study.

\section{REFERENCES}

Bradford M. M. (1976) A rapid and sensitive method for the quantitation of microgram quantities of protein utilizing the principle of protein-dye binding. Analyt. Biochem. 72 , 248-254

Carpenter G. (1981) Vanadate, epidermal growth factor, and the stimulation of DNA synthesis. Biochem. biophys. Res. Commun. 102, 1115-1121.

Charlier J-P., Petrovic A. and Herrmann-Stutzmann J.
(1969) Effects of mandibular hyperpropulsion on the prechondroblastic zonc of young rat condyle. $A m . J$ Orthod. 55, $71-74$.

Copray J. C. V. M., Janssen H. W. B. and Duterloo H. S (1985) Effect of compressive forces on phosphatase activ. ity in mandibular condylar cartilage of the rat in cirro. J. Anat 140, 479-489.

Emerson J. D. and Hoaglin D. C. (1983) Understanding Robust and Exploratory Data Analysis (Edited by Hoaglin D. C., Mosteller F. and Tukey J. W.) Chap. 6. pp. 166-182. Wiley Series in Probability and Mathe. matical Statistics, New York.

Enlow D. H. (1975) Handbook of Facial Grow'h, Chap. 2 , pp. 10-47. Saunders, Philadelphia, Penn.

Ferniey H. N. (1971) The Enzymes (Edited by Boyer P. D.) Vol. 4, 3rd edn, Chap. 18, pp. 417-447. Academic Press. New York

Hendricksen R. P., McNamara J. A. Carlson D. S. and Yellich G. M. (1982) Changes in the gonial angle region induced by alterations of muscle length. J. Oral Max. illofac. Surg. 40, 570-577.

Hoyte D. A. N. and Enlow D. H. (1966) Woltt's law and the problem of muscle attachment on resorptive surfaces of bone. Am. J. phy's. Anthrop. 24, 205-213

Kantomaa T. (1987) Reactions of the condylar tissues to attempts to increase mandibular growth. Scand. J. demt. Res. 95, 335-339.

Lanyon L. E. (1984) Functional strain as a determinant for bone remodelling. Calc. Tis. Int. suppl. 36, 56-61.

McNamara J. A. Jr (1973) Neuromuscular and skeletal adaptations to altered function in the orofacial region. Am. J. Orihod. 64, 578-606.

McNamara J. A. Jr and Carlson D. S. (1979) Quantitative analysi: of temporomandibular joint adaptations to protrusive function. $4 \mathrm{~m}$. J. Orthod 76, 593-611.

McNamara J. A. Jr and Bryan F. A. (1987) Long-term mandibular adaptations to protrusive function: an experimental study in Macacca mulatta. Am. J. Orthod. Dentofacial Orthop. 92, 98-108.

Vilsen R. and Magnusson B. C. (1981) Enzyme histochemical studies of induced heterotopic cartilage and bone formation in guinea pigs with special reference to acid phosphatase. Scand. J. dent. Res. 89, 49!-498.

Petrovic A. G., Stutzmann J. J. and Oudet C. L. (1975) Determinants of Mandibular Form and Growth (Edited by McNamara J. A. Jr) pp. 101-153. University of Michigan, Center for Human Growth and Development, Ann Arbor, Mich

Petrovic A. G. Stutzmann J. J. and Gasson N. (1981) Craniofacial Biology (Edited by Carlson D. S.) pp. 105-126. University of Michigan, Center for Human Growth and Development. Ann Arbor, Mich

Reddi A. H. and Huggins C. (1972) Biochemical sequences in the transformation of normal fibroblasts in adolescent rats. Proc natn. Acad. Sci. U.S.A. 69, 1601-1605.

Silbermann M. and Frommer J. (1973) Phosphatases within the cartilage of the mandibular condyle of the mouse. J. Anal. 116, 335-245.

Vilmann H. (1977) Phosphatases and bone growth. Scand J. dent Res. 85, 302-304.

Vinkka H. (1982) Secondary cartilages in the facial skeleton of the rat. Proc. Finn. dent. Soc. suppl. VII, $1 \ldots 137$ 


\section{Plate 1}

Fig. 1. (a) Lateral radiograph of the head of a 31-day-old experimental animal just before appliance fixation. Note normal overjet and overbite. (b) Similar radiograph showing the protrusive appliance. bonded to the upper incisors, protruding the mandible about $2 \mathrm{~mm}$ and opening the bite about $2 \mathrm{~mm}$. During normal daily activities the animals tend to position the mandible even more anteriorly in an attempt to find tooth contact. 

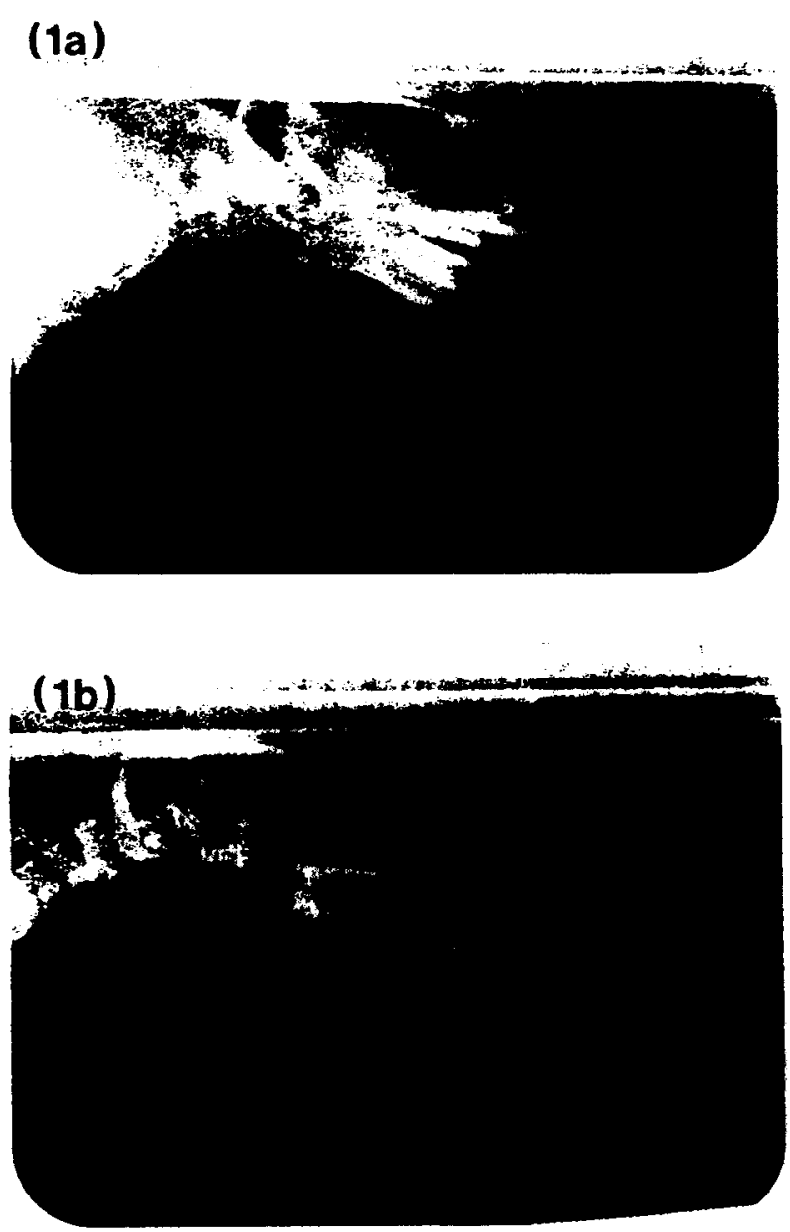

Plate I 